\title{
Progress in the chemotherapeutic treatment of osteosarcoma (Review)
}

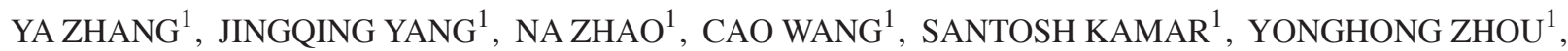 \\ ZEWEI HE ${ }^{1}$, JIFEI YANG ${ }^{1}$, BIN SUN ${ }^{2}$, XIAOQIAN SHI ${ }^{3}$, LEI HAN ${ }^{4}$ and ZUOZHANG YANG ${ }^{1}$ \\ ${ }^{1}$ Department of Orthopedics, The Third Affiliated Hospital of Kunming Medical University, Tumor Hospital of \\ Yunnan Province, Kunming, Yunnan 650118; ${ }^{2}$ Department of Orthopedics, The First Affiliated Hospital of \\ Kunming Medical University, Kunming, Yunnan 650000; ${ }^{3}$ Department of Pharmacy, The Third Affiliated Hospital of \\ Kunming Medical University, Tumor Hospital of Yunnan Province, Kunming, Yunnan 650118; ${ }^{4}$ Department of Radiology, \\ The Second Affiliated Hospital of Kunming Medical University, Kunming, Yunnan 650101, P.R. China
}

Received February 19, 2017; Accepted November 7, 2017

DOI: $10.3892 / \mathrm{ol} .2018 .9434$

\begin{abstract}
Osteosarcoma (OS) is the most common type of primary bone tumor in children and adolescents and has been associated with a high degree of malignancy, early metastasis, rapid progression and poor prognosis. However, the use of adjuvant chemotherapy improves the prognosis of patients with OS. OS chemotherapy is based primarily on the use of adriamycin, cisplatin (DDP), methotrexate (MTX), ifosfamide (IFO), epirubicin (EPI) and other drugs. Previous studies have revealed that the survival rate for patients with OS appears to have plateaued: 5-year survival rates remain close to $60 \%$, even with the use of combined chemotherapy. The most limiting factors include complications and fatal toxicity associated with chemotherapy agents, particularly high-dose MTX (HD-MTX), for which high toxicity and great individual variation in responses have been observed. Docetaxel (TXT) is a representative member of the relatively recently developed taxane class of drugs, which function to inhibit OS cell proliferation and induce apoptosis. Recently, more clinical studies have reported that TXT combined with gemcitabine (GEM) is effective in the treatment of OS (relapse/refractory and progressive), providing evidence in support of potential novel treatment strategies for this patient population. However, there is still no global consensus on this type of chemotherapy approach. The present review summarizes current studies surrounding progress in the chemotherapeutic treatment of OS and discusses the advantages and potential feasibility of TXT+GEM in the treatment of OS.
\end{abstract}

Correspondence to: Dr Zuozhang Yang, Department of Orthopedics, The Third Affiliated Hospital of Kunming Medical University, Tumor Hospital of Yunnan Province, 519 Kunzhou Road, Kunming, Yunnan 650118, P.R. China

E-mail: yangzuozhang@163.com

Key words: osteosarcoma, chemotherapy, methotrexate, docetaxel

\section{Contents}

1. Introduction

2. Conventional OS chemotherapy

3. Problems with chemotherapy

4. Second-line treatment of OS

5. Discussion

\section{Introduction}

Osteosarcoma (OS) is derived from primitive bone-forming mesenchymal cells and represents the most common primary bone malignancy in children and adolescents, with an annual incidence rate of $\sim 3$ per 100 million, though this rate is $\sim 50 \%$ higher in men than in women in the USA, $2016(1,2)$. OS exhibits a high degree of malignancy and tends to metastasize early: Lung metastasis is frequently observed in newly diagnosed patients, and pulmonary symptoms may develop within one year without chemotherapy (3). The main cause of mortality in patients with OS is lung metastasis, and approximately $10-20 \%$ of patients are diagnosed with metastatic OS upon identification of the disease in the USA, 2015 (4). Consequently, prognosis is often very poor $(5,6)$.

Prior to the 1950s, the treatment of OS depended primarily on surgical resection, with 5-year survival rates <20\% in 1972 in the USA (7-9). Since the introduction of effective chemotherapeutic agents in the 1970s and subsequent developments in neo-adjuvant chemotherapy, prognosis for such patients has greatly improved. The main chemotherapeutic agents for OS include adriamycin (ADM), cisplatin (DDP), methotrexate (MTX), cyclophosphamide (CTX) and epirubicin (EPI). Although some novel insights have been offered for clinical and scientific relevance, minor progress has been made in OS treatment following a significant survival improvement in the late 1980s with the addition of chemotherapy to surgery. In addition, prognosis of patients with recurrent or refractory OS is particularly poor. The function of second-line chemotherapy for recurrent OS is much less well defined and there is no accepted standard regimen (10-20). The purpose of the 
present article was to review the current state of the field and the opportunities for present and future treatment strategies in OS. Furthermore, informed consent was obtained from all individual participants included in the present study and all procedures performed in the studies involving human participants were in accordance with the ethical standards of the institutional and/or national research committee and with the 1964 Helsinki Declaration and its later amendments or comparable ethical standards.

\section{Conventional OS chemotherapy}

In the early $1950 \mathrm{~s}$, the primary treatment for OS involved surgical resection, with 5 -year survival rates $<20 \%$ in the USA $(5,6)$. Sun et al (21) reported that the dose and intensity of MTX are associated with the survival of patients with OS. Prior to the 1970s, Jaffe (22) and Rosen et al (23-25) treated OS with bleomycin, CTX, HD-MTX, vincristine and ADM following surgery, providing the first reported evidence for postoperative adjuvant chemotherapy in this patient population.

Adjuvant chemotherapy is defined as chemotherapy directed toward the site of the primary tumor following radical resection or radical radiotherapy, also known as postoperative or radiation chemotherapy. Such therapy aims at improving cure rates by eliminating small metastases (26,27). In 1982 , Eilber and Rosen (28) and Rosen (29) reviewed postoperative chemotherapy strategies in patients with OS, reporting a significant efficacy and thus forming the basis for neoadjuvant chemotherapy-important milestones in the history of OS treatment. Neoadjuvant chemotherapy was initiated prior to surgery according to the degree of the tumor response following chemotherapeutic treatment of the primary tumor. The T4 and T5 protocols were the first to incorporate neoadjuvant chemotherapy.

Current chemotherapy programs for OS have included the $\mathrm{T}$ protocols developed by Rosen (23) the Cooperative Osteosarcoma Study group protocol of the Germany and Austria OS Chemotherapy Collaborative Research Group and the treatment and investigation of osteosarcoma (TOIS) protocol developed by Jaffe et al (22) at the Rizzoli Institute of Chemotherapy in Italy. MTX, DDP, ADM and IFO are the four primary drugs used for OS chemotherapy (30). For almost 20 years, high-dose and multi-drug neoadjuvant chemotherapy has been the gold standard for OS treatment.

Currently, the majority of the scholars hypothesize that combined surgical removal of the tumor and systemic multi-drug chemotherapy consisting mainly of MTX, ADM and DDP (with or without IFO) represents the best strategy for the treatment of conventional OS. Two conventional chemotherapy regimens have been described: One involves the use of ADM $\left(45 \mathrm{mg} / \mathrm{m}^{2}\right)$ in combination with DDP $\left(100-120 \mathrm{mg} / \mathrm{m}^{2}\right)$, while the other involves the combined use of MTX $\left(8-12 \mathrm{~g} / \mathrm{m}^{2}\right.$ and $\left.12 \mathrm{~g} / \mathrm{m}^{2}\right)$, DDP $\left(120 \mathrm{mg} / \mathrm{m}^{2}\right)$ and $\operatorname{ADM}\left(60 \mathrm{mg} / \mathrm{m}^{2}\right)(31)$.

\section{Problems with chemotherapy}

The most common side effects of chemotherapy include myelosuppression and gastrointestinal reactions, which typically manifest as lower blood, nausea and vomiting. The main side effect of anthracycline antibiotics (doxorubicin and EPI) is cardiotoxicity, and the incidence of heart failure increases to 25-30\% when ADM doses exceed $550 \mathrm{mg} / \mathrm{m}^{2}$ (32). Furthermore, the side effects of DDP include kidney damage, hearing loss, hypomagnesemia and peripheral neuropathy. The most severe side effect of IFO is bladder toxicity, as the IFO metabolite acrolein can result in hemorrhagic cystitis.

HD-MTX is associated with serious and sometimes fatal toxicity. Previous studies have reported that the grade III-IV gastrointestinal reaction rate for HD-MTX is $49.32 \%$ whereas the rate of grade III-IV neutropenia is $30.13 \%(33,34)$. Several adverse nervous system reactions have also been associated with HD-MTX chemotherapy. At present, the use of HD-MTX chemotherapy remains limited due to the risk of potentially fatal MTX poisoning or bone marrow suppression $(35,36)$. A number of scholars have reported that patients exhibited adverse reactions of differing types and degrees following the use of the MTX-MTX-DDP/ADM regimen (37). Furthermore, certain studies have even reported a $100 \%$ rate of gastrointestinal reactions following MTX chemotherapy, mainly consisting of nausea and vomiting, as well as a $73.13 \%$ rate of oral mucositis; $80 \%$ rate of abnormal liver function [mainly associated with increases in alanine aminotransferase]; and a $17 \%$ incidence of leukopenia (38). Therefore, controversy remains regarding the use of multi-drug therapy involving HD-MTX for the treatment of OS. Thus, it remains crucial to elucidate whether such chemotherapeutic methods are both safe and effective.

In total, approximately $30-40 \%$ of patients are diagnosed with advanced stage OS upon clinical confirmation, with roughly $50 \%$ of patients experiencing postoperative recurrence (39). Although chemotherapy significantly improves the prognosis of patients with non-metastatic OS, patients are often forced to cease and modify chemotherapy regimens due to drug resistance, toxicity, and/or side effects. Furthermore, chemotherapy cannot effectively control tumor metastasis and progression. Almost 10 years of research has revealed that the survival rate for patients with OS has reached a plateau: The 5-year survival rate remains $\sim 60 \%$, even when combined chemotherapy is used (40). The 5-year survival rate for patients with pulmonary metastases in the early stage of treatment, however, remains lower than $20 \%$. In total, approximately $25-50 \%$ of patients experience lung metastasis even during chemotherapy. Therefore, lung metastasis represents the main roadblock for improving survival rates in patients with OS (41).

With the advent of adjuvant and neoadjuvant chemotherapy, the survival rate of patients with OS has gradually increased, although $20-40 \%$ of patients still experience local recurrence or distant metastasis. Therefore, it is necessary to develop novel chemotherapeutic agents for the treatment of OS and to establish standards for second-line OS chemotherapy, which also remains controversial (42). Such developments may aid in improving the prognosis of patients with recurrent, metastatic or resistant OS.

Therefore, continuing research into novel treatment and all types of developed therapeutic forms is required (Fig. 1).

\section{Second-line treatment of OS}

OS is characterized by an onset during childhood or adolescence, a high degree of malignancy, early metastasis, rapid progression and poor prognosis (43). Multiple investigators 


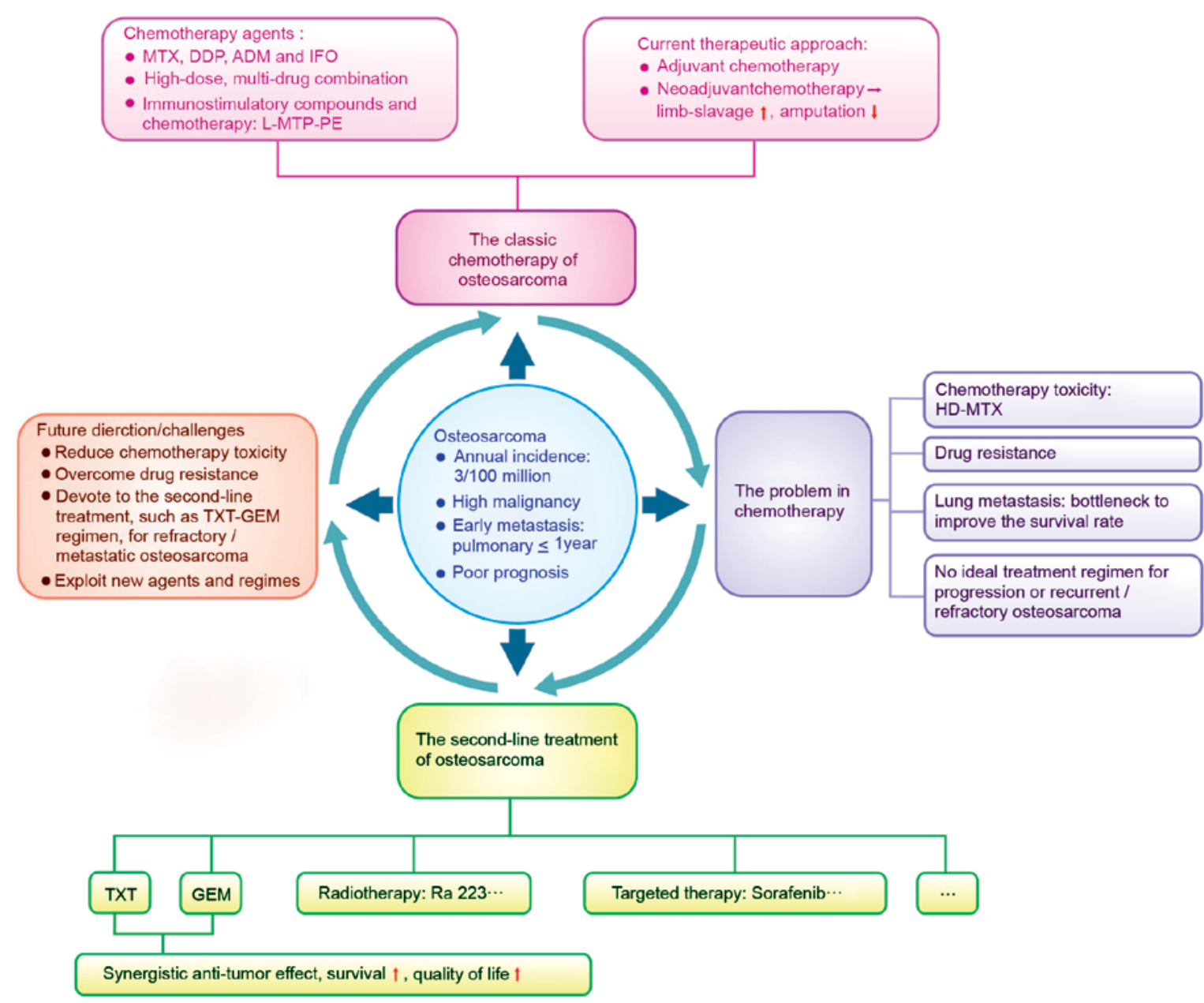

Figure 1. A synopsis model of osteosarcoma: Questions to be answered and future challenges. MTX, methotrexate; DDP, cisplatin; ADM, adriamycin; IFO, ifosfamide; L-MTP-PE, liposomal muramyl tripeptide phosphatidyl ethanolamine; TXT, docetaxel; GEM, gemcitabine; HD, high-dose.

have indicated that patients receive second-line therapy in the event of recurrence or metastasis $(44,45)$. Furthermore, the National Comprehensive Cancer Network (NCCN) guidelines (version 2.2016) recommend that second-line therapy include TXT, GEM, CTX, etoposide (VP-16), topotecan (TPT), carboplatin, samarium lexidronam ( $\left.{ }^{153} \mathrm{Sm}-\mathrm{EDTMP}\right), \mathrm{Ra} 223$, sorafenib and everolimus (46). Recent studies have focused mainly on the use of GEM, TXT or a combination of the two for second-line OS treatment (Tables I and II).

Docetaxel (TXT). TXT is a non-cytotoxic precursor derived from the needles of Taxus specimens that has been chemically modified to yield a taxol-type antitumor agent that is threefold higher in intracellular concentration than paclitaxel. TXT also exhibits long residence time in the cell (42). It acts mainly through the promotion of stable microtubule polymerization and the inhibition of depolymerization, thereby significantly reducing the number of free microtubules, inhibiting spindle separation at the two poles, blocking the $\mathrm{G}$ and $\mathrm{M}$ phases and ultimately inhibiting tumor cell mitosis and proliferation (47).

Certain scholars have reported that TXT can inhibit the proliferation of OS cells and induce apoptosis, and that such inhibition is time- and dose-dependent $(48,49)$. Combination therapy using TXT and gemcitabine (GEM) has also been reported to enhance antitumor effects $(50,51)$. A number of scholars (52) have used chemotherapy-related drug target gene detection via the application of second-generation high-throughput sequencing technology in patients with OS undergoing surgical resection. The results of such studies indicate that TXT induces OS cell apoptosis, and that OS cells can achieve moderate TXT sensitivity (53.3\%).

Palmerini et al (53) used TXT chemotherapy for 14 cases of recurrent OS, 1 case of partial remission, and 1 case involving a patient in stable condition. Zwerdling et al (54) used single-drug TXT chemotherapy, reporting 1-year and 5 -year overall survival rates of 24 and 6\%, respectively. These observations indicate that such approaches may be useful in the treatment of metastatic and relapsed/refractory OS, and OS that is unresponsive to first-line treatment.

GEM. GEM is a fluorinated analog of the nucleoside deoxycytidylic acid, which is converted into active diphosphate and nucleoside triphosphates by the action of nucleoside kinases in the cell. Diphosphate inhibits ribonucleotide reductase and is involved in deoxycytidine triphosphate competition as a nucleoside triphosphate. Ribonucleotide reductase inhibition can activate self-generating mechanisms, thereby increasing the entry of nucleotides into cells. DNA synthesis terminates when the GEM triphosphate metabolite enters the DNA to produce additional nucleotides. This mechanism can develop 
Table I. Osteosarcoma systemic therapy agents of the NCCN guidelines.

Agent

(Refs.)

First-line therapy (primary/neoadjuvant/adjuvant therapy or metastatic disease)

Cisplatin and doxorubicin

MAP (high-dose methotrexate, cisplatin, and doxorubicin)

Doxorubicin, cisplatin, ifosfamaide, and high-dose methotrexate

Ifosfamide, cisplatin, and epirubicin

Second-line therapy (relapsed/refractory or metastatic disease)

Docetaxel and gemcitabine

Cyclophosphamide and etoposide

Cyclophosphamide and topotecan

Gemcitabine

Ifosfamide (high dose)+/- etoposide

Ifosfamide, carboplatin and etoposide

High-dose methotrexate, etoposide and ifosfamide

${ }^{153} \mathrm{Sm}$-EDTMP for relapsed or refractory disease beyond second-line therapy

Ra223

Sorafenib

Sorafenib+everolimus

NCCN, National Comprehensive Cancer Network; ${ }^{153} \mathrm{Sm}$-EDTMP, samarium lexidronam.

resistance to DNA repair enzymes, which may represent a mechanism for overcoming drug resistance (55). The results of a small-sample phase II clinical trial have indicated that the effective rate of GEM monotherapy is $<10 \%$. Recent studies $(47,53,56,57)$ have also indicated that TXT can increase the expression of thymidine phosphorylase in tumor tissue, thereby enhancing the antitumor activity of GEM, resulting in synergistic antitumor effects ranging from $17-30 \%$ (58). He et al (51) reported that $80 \%$ of patients [median OS duration: 13 months; median progression-free survival (PFS): 6-7 months] receiving GEM in combination with TXT as second-line therapy experienced 12- and 24-month survival rates of 66 and $80 \%$, respectively.

Qi et al (48) treated 18 patients with relapsed/refractory OS using TXT combined with GEM, reporting a tumor control rate of the rate $[(\mathrm{CR}+\mathrm{PR}+$ stable disease $(\mathrm{SD})]$ of $22.3 \%$ and a median overall survival of 8 months. Furthermore, Mora et al (59) used the same chemotherapy protocol, reporting a remission rate $(\mathrm{CR}+\mathrm{PR})$ of $50 \%$ and a median remission duration of 10 months. O'Day and Gorlick (60) reported that the overall response rate of patients with OS was $43 \%$ following combined TXT+GEM chemotherapy. Song et al (55) also reported a response rate $(\mathrm{CR}+\mathrm{PR})$ of $23.5 \%$ and a control rate $(\mathrm{CR}+\mathrm{PR}+\mathrm{SD})$ of $41.2 \%$, with a 1 -year overall survival rate of $53.6 \%$ and a median remission duration of 11.2 months in patients receiving TXT+GEM for recurrent/refractory OS. Certain scholars have also applied this strategy for the treatment of patients undergoing limb-salvage surgery, reporting remission rates of $13.0 \%$ and a median overall survival period of 9 months (51). Additional studies have added arsenic trioxide $\left(\mathrm{As}_{2} \mathrm{O}_{3}\right)$ to the TXT+GEM combination regimen for the treatment of first-line chemotherapeutic drug resistance in patients with OS lung metastasis, reporting an overall effective rate (CR+PR) of 34.6\%, along with 1-,2-, and 4-year survival rates of $61.5,38.4$ and $15.4 \%$, respectively (55). Additional studies have also reported disease control rates between $28.5-41.2 \%(55,58)$ and median overall survival times of 7-11 months following TXT+GEM treatment in patients with refractory/metastatic OS (53). Therefore, the TXT+GEM regimen, for which a relatively larger amount of evidence has been reported relative to other recommended regimens, was the first to be recommended (51) (as shown in Table II).

Targeted therapy. Sorafenib acts to inhibit a variety of kinases present in the cell and at the cell surface, including RAF kinase, vascular endothelial growth factor receptor-2, vascular endothelial growth factor receptor-3, platelet derived growth factor receptor- $\beta$, KIT Proto-Oncogene Receptor Tyrosine Kinase (KIT) and Fms Related Tyrosine Kinase 3 (FLT-3). A recent phase II study revealed that the median PFS was 4 months for sorafenib-treated patients with first-line failure and unresectable OS, with a clinical benefit rate of 29 and a $17 \%$ increase in clinical benefit after 6 months (61). Such observations provide the first evidence for the efficacy of small-molecule agents targeted toward the second-line treatment of lung metastasis in OS.

Everolimus. Everolimus is a derivative of sirolimus (also known as rapamycin), which is a classical inhibitor of the mechanistic target of rapamycin target and a novel macrolide immunosuppressive agent. Rapamycin prevents T lymphocytes and other cells from transitioning from the $G_{1}$ to $S$ phases via blockage of signaling pathways involving various cytokines, which serve an important role in immunosuppression. Grignani et al $(61,62)$ speculate that sorafenib and combined therapy using sorafenib and everolimus are promising for 
Table II. Evidence which support the Docetaxel+Gemcitabine regimens are recommended to osteosarcoma.

\begin{tabular}{|c|c|c|c|c|}
\hline Authors & $\begin{array}{l}\text { Number of } \\
\text { patients }\end{array}$ & Drugs & Outcomes & (Refs.) \\
\hline Yu et al & 39 & $\begin{array}{l}21 \text { cases: Gemcitabine }\left(675 \mathrm{mg} / \mathrm{m}^{2} \mathrm{~d} 1 \text {, }\right. \\
\mathrm{d} 8)+ \text { docetaxel }\left(100 \mathrm{mg} / \mathrm{m}^{2} \mathrm{~d} 8\right) \\
18 \text { cases: Pemetrexed }\left(500 \mathrm{mg} / \mathrm{m}^{2} \mathrm{~d} 1\right)+ \\
\text { cisplatin }\left(100 \mathrm{mg} / \mathrm{m}^{2} \mathrm{~d} 1\right)\end{array}$ & $\begin{array}{l}\text { The response rate was } 25.0 \% \text { in patients who } \\
\text { received pirarubicin-based chemotherapy, } \\
\text { while it was } 13.0 \% \text { in the gemcitabine- } \\
\text { docetaxel group. Moreover, the median OS } \\
\text { was longer in the pirarubicin-based } \\
\text { chemotherapy group ( } 14.0 \text { vs. } 9.0 \text { months, } \\
\text { P<0.05), particularly in the pirarubicin-ifosfamide } \\
\text { ( } 14.0 \text { months) and pirarubicin-cisplatin } \\
\text { ( } 15.0 \text { months) subgroups. }\end{array}$ & $(58)$ \\
\hline He et al & 75 & $\begin{array}{l}23 \text { cases: Gemcitabine }\left(675 \mathrm{mg} / \mathrm{m}^{2} \mathrm{~d} 1 \text {, }\right. \\
\mathrm{d} 8)+ \text { docetaxel }\left(100 \mathrm{mg} / \mathrm{m}^{2} \mathrm{~d} 8\right) \\
52 \text { cases: THP-based chemotherapy } \\
\text { (THP-CDDP, THP-IFO, or THP-PTX) }\end{array}$ & $\begin{array}{l}13 \text { patients }(25.0 \%) \text { in the THP group and } 3 \\
(13.0 \%) \text { in the GT group achieved a PR, while } \\
23 \text { patients }(44.2 \%) \text { in the THP group and } 8 \\
(34.8 \%) \text { in the GT group showed SD. Thus, } \\
\text { RRs in the } 2 \text { groups were } 25.0 \text { and } 13.0 \% \\
(\mathrm{P}=0.414) \text {, and DCRs were } 69.2 \text { and } 47.8 \% \\
(\mathrm{P}=0.127)\end{array}$ & (51) \\
\hline Qi et al & 18 & $\begin{array}{l}\text { Gemcitabine }\left(675 \mathrm{mg} / \mathrm{m}^{2} \mathrm{~d} 1, \mathrm{~d} 8\right)+ \\
\text { docetaxel }\left(100 \mathrm{mg} / \mathrm{m}^{2} \mathrm{~d} 8\right)\end{array}$ & $\begin{array}{l}\text { The overall response rate was } 5.6 \% \text { and the } \\
\text { disease control rate was } 22.3 \% \text {, with } 1 \text { partial } \\
\text { response and } 3 \text { patients with stable disease. } \\
\text { The median time to progression and overall } \\
\text { survival time were } 2 \text { months (range: } 2-6 \\
\text { months) and } 8 \text { months (range: } 3-21 \text { months) }\end{array}$ & (48) \\
\hline Mora et al & 10 & $\begin{array}{l}\text { Gemcitabine }\left(675 \mathrm{mg} / \mathrm{m}^{2} \mathrm{~d} 1, \mathrm{~d} 8\right)+ \\
\text { docetaxel }\left(100 \mathrm{mg} / \mathrm{m}^{2} \mathrm{~d} 8\right)\end{array}$ & $\begin{array}{l}4(40 \%) \text { patients had a CR, } 1(10 \%) \text { had a } \\
\text { PR, } 3(30 \%) \text { had SD and } 2(20 \%) \text { had a PD, } \\
\text { which provides an objective response rate } \\
(\mathrm{CR}+\mathrm{PR}) \text { of } 50 \% \text {. Median duration of } \\
\text { response (CR+PR+SD) was } 10 \text { months } \\
\text { (range: } 6 \text { to } 32+\text { mo). } 5 \text { out of the } 10 \text { patients } \\
(50 \%) \text { are alive, with a median follow-up of } \\
48 \text { months from diagnosis. }\end{array}$ & (59) \\
\hline O'Day et al & 35 & $\begin{array}{l}\text { Gemcitabine }\left(675 \mathrm{mg} / \mathrm{m}^{2} \mathrm{~d} 1, \mathrm{~d} 8\right)+ \\
\text { docetaxel }\left(100 \mathrm{mg} / \mathrm{m}^{2} \mathrm{~d} 8\right)\end{array}$ & $\begin{array}{l}\text { All response rate } 43 \% ; 29 \%(\mathrm{CR}+\mathrm{PR}) ; 2 \text { out of } 4 \\
\text { osteosarcoma achieve PR. }\end{array}$ & (60) \\
\hline Palmerini et al & 51 & $\begin{array}{l}\text { Gemcitabine }\left(900 \mathrm{mg} / \mathrm{m}^{2} \mathrm{~d} 1, \mathrm{~d} 8\right)+ \\
\text { docetaxel }\left(75 \mathrm{mg} / \mathrm{m}^{2} \mathrm{~d} 8\right)\end{array}$ & $\begin{array}{l}\text { Four-month PFS rate was } 46 \% ; 6(13 \%) \text { patients } \\
\text { had a PR, } 20(43 \%) \text { had SD and } 20(43 \%) \text { had } \\
\text { PD. The 1-year OS was } 30 \%: 67 \% \text { for } \\
\text { PR, } 54 \% \text { for SD and } 20 \% \text { for PD }(P=0.005) .\end{array}$ & (53) \\
\hline
\end{tabular}

OS, osteosarcoma; THP, Therarubicin; GT, Gemcitabine+docetaxel; CR, complete response; PR, partial response; CDDP, cisplatin; IFO, ifosfamide; PTX, Paclitaxel; SD, stable disease; RR, Relative risk; DCR, Disease control rate; CR, control rate; PD, progressive disease; PFS, progression-free survival.

the treatment of patients with advanced or unresectable OS, although they did not attain the prespecified target of $50 \%$ or greater PFS within 6 months.

CTX. CTX is a bifunctional alkylating and cell cycle nonspecific agent that interferes with the DNA and RNA function, exerting its most apparent effects during the $S$ phase via DNA cross-linking and inhibition of DNA synthesis. CTX first transforms into aldehydes and phosphorus amide in the liver in vitro and without antitumor activity. However, aldehyde amide in tumor cells is transformed into amide nitrogen mustard and acrolein, which exert cytotoxic effects.

Etoposide. Etoposide is a cell cycle-specific antitumor drug that acts on DNA topoisomerase II to form the reversible complex of drug-enzyme-DNA stabilization, thereby hindering DNA repair. This complex can be reversed by cessation of drug treatment, so that the damaged DNA undergoes repair and cytotoxicity is reduced.

A phase II study reported that combined treatment using CTX and etoposide X2 arrested OS progression in a significant 
Table III. Strategies for target treatment of osteosarcoma and its representative drugs/compounds.

\begin{tabular}{|c|c|}
\hline Strategy & Drugs/compounds \\
\hline Novel delivery mechanisms & SLIT cisplatin (aerosolized liposomal formulation) \\
\hline \multicolumn{2}{|l|}{ Overcoming drug resistance } \\
\hline Inhibition of cellular DNA synthesis and cell growth & Gemcitabine \\
\hline Induction of apoptosis and cell cycle arrest & Doxetacel \\
\hline Novel antifolates & Trimetrexate (does not require $\mathrm{RCF}$ for transport into cell) \\
\hline Inhibition of drug efflux & Curcumin \\
\hline \multicolumn{2}{|l|}{ Inhibition of signaling receptors and transduction } \\
\hline IGF/IGF-1R pathway & Robatumumab, Figitumumab, Cixutumumab \\
\hline mTOR pathway & Ridaforolimus, Everolimus \\
\hline Src pathway & Sorafenib, Dasatinib, Saracatinib \\
\hline HER2-overexpression & Trastuzumab \\
\hline \multicolumn{2}{|l|}{ Altering the tumor microenvironment } \\
\hline \multicolumn{2}{|l|}{ Inhibition of osteoclast-mediated bone destruction } \\
\hline Bisphosphonates & Zoledronic acid, Pamidronate \\
\hline RANKL inhibitors & Denosumab \\
\hline \multicolumn{2}{|l|}{ Inhibition of angiogenesis } \\
\hline VEGF inhibitors & Bevacizumab \\
\hline Collagen XVIII-a 1 & Endostar \\
\hline
\end{tabular}

number of patients (54\%), with a relatively good tolerability and self-limiting toxicity that was resolved in all cases (11).

TPT. TPT is an inhibitor of topoisomerase I, which binds to the topoisomerase I-DNA complex and prevents reconnection of these single strand breaks. TPT is an S-phase specific drug whose cytotoxicity influences the synthesis of DNA. Saylors et al (12) reported that the combination of CTX and TPT is effective in the treatment of rhabdomyosarcoma, neuroblastoma and Ewing's sarcoma. Stabilization of disease was also observed in patients with OS, although objective responses were rare. Furthermore, TPT therapy can be initiated within the range of acceptable hematopoietic toxicity with the use of filgrastim support.

IFO. IFO is a cell-cycle nonspecific drug that is mainly activated by hydrolysis of the first four carbons, following which 4-hydroxy-IFO automatically forms aldehyde IFO, which decomposes into phosphorus amide nitrogen mustard and acrolein. The cytotoxic effect of IFO influences cross-linking with DNA. The cell cycle increases in proportion to $\mathrm{G}_{2}+\mathrm{M}$, and the $\mathrm{G}_{2}$ phase is delayed following administration of IFO. Magnan et al (63) conducted a retrospective chart review and reported that high doses of IFO resulted in a 4-year event-free survival (EFS) rate of $27 \%$ and an overall survival rate of $39 \%$.

The combination of etoposide and high-dose IFO is effective for induction of chemotherapy in patients with metastatic OS (3). Le Deley et al (17) reported a 5-year EFS rate of $62 \%$ for the entire study population, which was slightly higher in the
etoposide-IFO arm than in the doxorubicin arm. Furthermore, the 5-year overall survival rate of the entire population was $76 \%$. In total, $43 \%$ of patients in the etoposide-IFO arm were event-free at 3 years without having received any doxorubicin or DDP, thus avoiding the risk of long-term cardio- and cardiotoxicity.

Pemetrexed. Pemetrexed is a multi-target antifolate agent that significantly inhibits thymidylate synthase, dihydrofolate reductase and glycine ribonucleoside formyl transferase to interfere with folic acid metabolic pathways. Studies have revealed that such treatment may be effective as second-line chemotherapy in patients with MTX-resistant OS (45). Endostar has been combined with pemetrexed for the treatment of recurrent, drug-resistant OS and pulmonary metastases of OS. Furthermore, recent observations indicate that this treatment is effective and results in significant improvements in the quality of life without significant adverse reactions (64-67). Although trial results regarding second-line chemotherapy with pemetrexed for patients with OS lung metastases have been positive, further evidence regarding monotherapy and combination therapy using this agent is required.

Liposome-encapsulated muramyl tripeptide-phosphatidyl ethanolamine (L-MTP-PE). L-MTP-PE is an analog of muramyl dipeptide with the ability to activate macrophages and monocytes. Phase III clinical trials have indicated that L-MTP-PE can enhance immune system function (68). Mori et al (69) reported that infusion of L-MTP-PE can reduce 
the recurrence of lung metastases following surgery, and that the survival rate was higher than that of patients in the concurrent chemotherapy group. In recent years, L-MTP-PE has gained attention for its effects on pulmonary metastasis of OS and may prove effective as a second-line chemotherapy agent.

Samarium-153 ethylenediaminetetramethylene phosphonate. The ${ }^{153} \mathrm{Sm}$ nuclide is ideal for the diagnosis and treatment in nuclear medicine and is mainly used in the preparation of therapeutic radiopharmaceuticals, including ${ }^{153} \mathrm{Sm}$-EDTMP (ethylene diamine tetramethylene phosphonic acid ethylene diamine tetramethylene phosphonic acid), which has a high affinity for pro-tumor characteristics and bone. This agent has been used to treat bone metastases and relieve bone pain, although it can also be used for the treatment of primary bone cancer. Furthermore, bone-specific irradiation can be induced using ${ }^{153} \mathrm{Sm}$-EDTMP with peripheral-blood progenitor-cell support (70).

Radium 223 chloride. Radium 223 chloride, an $\alpha$-particle radioactive material, was the first particle to be used in radiation therapy drugs. The use of this agent is advantageous in that $95 \%$ of the decay can be released in the form of $\alpha$-particles, resulting in less damage to normal cells. Radium 223 chloride simulates the main constituent of bone calcium, although the actual course of treatment requires 6 injections/month. Furthermore, the drug is transferred to sites with metabolically active cells and metastatic bone cancer cells following injection. $\alpha$-particles are then released, resulting in the inhibition of bone metastases and cancer cell proliferation. Radium-223 is associated with low marrow toxicity and increased radiobiological effectiveness, particularly in bone-forming types of cancer, when compared with samarium-153-EDTMP $(18,19)$. Radium 223 may have greater potential for widespread use against bone metastases in OS since it may achieve safe and effective decrease of tumor burden and facilitate improvements in surgery and/or radiotherapy in patients with unresectable, large or metastatic tumors.

Multiple molecular-based therapies have also been developed for the treatment of OS, including anti-C-X-C chemokine receptor type 4 drugs (71), matrix metalloproteinase inhibitors, selective cyclooxygenase-2 inhibitors (72), type 1 insulin like growth factor receptor, and osteoclast-targeted therapy (73) The main factors affecting the function of osteoclasts are receptor activator $\mathrm{NF}-\kappa \beta$ ligands, osteoprotective proteins, bisphosphonates and Src inhibitors (74) However, targeted therapies also produce resistance and adverse effects (Table III), thus necessitating further investigation $(61,75-78)$.

\section{Discussion}

OS is the most common primary malignancy observed in children and adolescents (1). With the advent of adjuvant and neoadjuvant chemotherapy, the survival rate of patients with OS has gradually increased, although $20-40 \%$ of patients still experienced distant metastasis or local recurrence in 2014 (79). Despite major discoveries over the past 35 years, the survival rate for OS has plateaued, remaining at $\sim 60 \%$ even when combined therapy is used in China in 2015 (80). A previous study revealed that multidrug-associated chemotherapy is superior to single-drug and high dose-intensity chemotherapy, although there is considerable agreement among experts regarding the cytotoxicity of these agents (81). The blind pursuit of high-intensity doses increases the cost and complications of chemotherapy, as well as the risk of fatal toxicity, which has been reported to be as high as $4.3 \%$ (32). In particular, HD-MTX is highly toxic and associated with great variation in individual responses. Furthermore, patients are often forced to terminate or modify their chemotherapy regimens due to drug resistance or intense side effects, thus making it difficult to gain definitive control over the progression and metastasis of tumors.

The stagnation in survival rates is principally associated to the fact that the arsenal of available effective chemotherapeutic agents has not changed substantially over the past decade. Therefore, novel agents and alternative strategies to combat this malignancy are required. Advances in research concerning tumor growth, chemoresistance, gene therapy and targeted molecular therapy will allow for the development of multidisciplinary approaches for the treatment of OS. Progress has also been made in the areas of antitumor angiogenesis therapy, tumor immunotherapy and tumor drug resistance (82). However, in 1993, 20-30\% of all patients in USA exhibited clinically detectable metastatic OS when they were initially diagnosed (83). The great heterogeneity of these tumors often conveys resistance to drugs, giving rise to relapse and metastasis (84). Therefore, the requirement to develop novel drugs and treatment strategies for patients with OS relapse/metastasis remains urgent.

The NCCN recommends that patients receive second-line treatment in the event of disease progression during first-line treatment (44). At present, several novel chemotherapy agents are undergoing investigation, including GEM, TXT and a combination of the two. Studies have revealed that TXT may inhibit proliferation and induce apoptosis of OS cells, and that the sensitivity of OS cells to TXT is high, providing a novel method of treatment for patients with refractory OS or those in whom relapse or metastasis have occurred. Furthermore, a retrospective case study reported that TXT combined with GEM for the treatment of relapsed, refractory or metastatic OS is significantly effective (85), while other studies have revealed that patients benefit from such combination strategies, even when lower dosages are used (47).

Recent studies have revealed that TXT can increase the expression of thymidine phosphorylase in tumor tissue, thereby enhancing the antitumor activity of GEM, resulting in synergistic antitumor effects, and that such treatment is well-tolerated $(55,86)$. These observations also represent a novel method for effective and comprehensive treatment of OS.

However, the most recent studies on these novel agents have been small, retrospective analyses, while phase III clinical data are lacking when compared with observations regarding conventional chemotherapy. Additional large, multicenter, randomized controlled trials and phase II trials are required in order to validate the efficacy and safety of TXT+GEM in the treatment of OS, as well as the appropriate chemotherapy regimens and doses. Finally, continuing research into novel treatment and all types of developed therapeutic forms is required.

\section{Acknowledgements}

Not applicable. 


\section{Funding}

The present review was supported by the Joint Special Funds for the Department of Science and Technology of Yunnan Province-Kunming Medical University (grant no. 2014FB059, grant no. 2018NS0069, grant no. 2018NS0070).

\section{Availability of data and materials}

Not applicable.

\section{Authors' contributions}

Study concept and design was the responsibility of YZ, YHZ and ZY. YZ, JY, NZ and CW searched references. NZ and $\mathrm{CW}$ acquired data and new ideas from references and analysed and interpreted this information Manuscript preparation was undertaken by YZ, YHZ, SK, YZ, ZH, JY, NZ, CW and BS. YZ, XS, LH, ZY performed a manuscript review. All authors read and approve the final manuscript.

\section{Ethics approval and consent to participate}

Not applicable.

\section{Patient consent for publication}

Not applicable.

\section{Competing interests}

All authors declare that there have no competing interests.

\section{References}

1. Genetic and Rare Diseases Information Center (GARD), supported by ORDR-NCATS and NHGRI. http://www.diseaseinfosearch.org/result/5489

2. Harrison DJ, Geller DS, Gill JD, Lewis VO and Gorlick R: Current and future therapeutic approaches for osteosarcoma Expert Rev Anticancer Ther 18: 39-50, 2018.

3. Huang KL, Chen CF, Wu PK, Chen PC, Chen WM, Liu CL and Chen TH: Clinical outcomes and prognostic factors of Ewing sarcoma: A clinical analysis of 12 patients in Taiwan. J Chin Med Assoc 75: 16-20, 2012.

4. Ren L, Mendoza A, Zhu J, Briggs JW, Halsey C, Hong ES, Burkett SS, Morrow J, Lizardo MM, Osborne T, et al: Characterization of the metastatic phenotype of a panel of established osteosarcoma cells. Oncotarget 6: 29469-29481, 2015

5. Janeway KA and Grier HE: Sequelae of osteosarcoma medical therapy: A review of rare acute toxicities and late effects. Lancet Oncol 11: 670-678, 2010.

6. Bernthal NM, Federman N, Eilber FR, Nelson SD, Eckardt JJ, Eilber FC and Tap WD: Long-term results ( $>25$ years) of a randomized, prospective clinical trial evaluating chemotherapy in patients with high-grade, operable osteosarcoma. Cancer 118: $5888-5893,2012$

7. Friedman MA and Carter SK: The therapy of osteogenic sarcoma: Current status and thoughts for the future. J Surg Oncol 4: 482-510, 1972

8. Marina N, Gebhardt M, Teot and Gorlick R: Biology and therapeutic advances for pediatric osteosarcoma. Oncologist 9: 422-441, 2004.

9. Bacci G, Mercuri M, Briccoli A, Ferrari S, Bertoni F, Donati D, Monti C, Zanoni A, Forni C and Manfrini M: Osteogenic sarcoma of the extremity with detectable lung metastases at presentation. Results of treatment of 23 patients with chemotherapy followed by simultaneous resection of primary and metastatic lesions. Cancer 79: 245-254, 1997.
10. Navid F, Willert JR, McCarvile MB, Furman W, Watkins A, Roberts W and Daw NC: Combination of gemcitabine and docetaxel in the treatment of children and young adults with refractory bone sarcoma. Cancer 113: 419-425, 2008.

11. Berger M, Grignani G, Ferrari S, Biasin E, Brach del Prever A, Aliberti S, Saglio F, Aglietta M and Fagioli F: Phase 2 trial of two courses of cyclophosphamide and etoposide for relapsed high-risk osteosarcoma patients. Cancer 115: 2980-2987, 2009.

12. Saylors RL III, Stine KC, Sullivan J, Kepner JL, Wall DA, Bernstein ML, Harris MB, Hayashi R and Vietti TJ; Pediatric Oncology Group: Cyclophosphamide plus topotecan in children with recurrent or refractory solid tumors: A pediatric oncology group phase II study. J Clin oncol 19: 3463-3469, 2001.

13. Maki RG, wathen, JK, Patel SR, Priebat DA, Okuno SH, Samuels B, Fanucchi M, Harmon DC, Schuetze SM, Reinke D, et al: Randomized phase II study of gemcitabine and docetaxel compared with gemcitabine alone in patients with metastatic soft tissue sarcoma: Results of sarcoma alliance for research through collaboration study 002 [corrected]. J Clin Oncol 25: 2755-2763, 2007.

14. Miser JS, Kinsella TJ, Triche TJ, Tsokos M, Jarosinski P, Forquer R, Wesley R and Magrath I: Ifosfomide with mesna uroprotection and etoposide: An effective regimen in the treatment of recurrent sarcomas and other tumors of children and young adults. J Clin Oncol 5: 1191-1198, 1987.

15. Goorin AM, Harris MB, Bernstein M, Ferguson W, Devidas M, Siegal GP, Gebhardt MC, Schwartz CL, Link M and Grier HE: Phase II/III trial of etoposide and high-dose ifosfamide in newly diagnosed metastatic osteosarcoma: A pediatric oncology group trial. J Clin Oncol 20: 426-433, 2002.

16. Van Winkle P, Angiolillo A, Krailo M, Cheung YK, Anderson B, Davenport V, Reaman G and Cairo MS: Ifosfamide, carboplatin, and etoposide (ICE) reinduction chemotherapy in a large cohort of children and adolescents with recurrent/refractory sarcoma: The children's cancer group (CCG) experience. Pediatr Blood Cancer 44: 338-347, 2005.

17. Le Deley MC, Guinebretière JM, Gentet JC, Pacquement $H$, Pichon F, Marec-Bérard P, Entz-Werlé N, Schmitt C, Brugières L, Vanel D, et al: SFOP OS94: A randomized trial comparing preoperative high-dose methotrexate plus doxorubicin to high-dose methotrexate plus etoposide and ifosfamide in osteosarcoma patients. Eur J Cancer 43: 752-761, 2007.

18. Anderson PM, Subbiah V and Rohren E: Bone-seeking radiopharmaceuticals as targeted agents of osteosarcoma: Samarium-153-EDTMP and radium-223. Adv Exp Med Boil 804: 291-304, 2014.

19. Subbiah V, Rohren E, Huh WW, Kappadath CS and Aderson PM: Phase 1 dose escalation trial of intravenous radium 223 dichloride alpha-particle therapy in osteosarcoma. J Clin Oncol 32 (15-Suppl): Abstract TPS 10600, 2014.

20. Grignani G, Palmerini E, Ferraresi V, D'Ambrosio L, Bertulli R, Asaftei SD, Tamburini A, Pignochino Y, Sangiolo D, Marchesi E, et al: Sorafenib and everolimus for patients with unresectable high-grade osteosarcoma progression after standard treatment: A non-radomised phase 2 clinical trial. Lancet Oncol 16: 90-107, 2015.

21. Sun L, Li Y, Li H, Zhang J, Li B and Ye Z: Analysis of chemotherapy dosage and dosage intensity and survival outcomes of high-grade osteosarcoma patients younger than 40 years. Clin Ther 36: 567-578, 2014.

22. Jaffe N: Recent advances in the chemotherapy of metastatic osteogenic sarcoma. Cancer 30: 1627-1631, 1972.

23. Rosen G, Marcove RC, Caparros B, Nirenberg A, Kosloff C and Huvos AG: Primary osteogenic sarcoma: The rationale for preoperative chemotherapy and delayed surgery. Cancer 43: 2163-2177, 1979.

24. Rosen G and Nirenberg A: Neoadjuvant chemotherapy for osteogenic sarcoma: A five year follow-up (T-10) and preliminary report of new studies (T-12). Prog Clin Biol Res 201: 39-51, 1985.

25. Rosen G: Preoperative (neoadjuvant) chemotherapy for osteogenic sarcoma: A ten year experience. Orthopedics 8: 659-664, 1985.

26. Thiele OC, Freier K, Bacon C, Egerer G and Hofele CM: Interdisciplinary combined treatment of craniofacial osteosarcoma with neoadjuvant and adjuvant chemotherapy and excision of the tumour: A retrospective study. Br J Oral Maxillofac Surg 46: 533-536, 2008.

27. Meyers PA, Heller G, Healey J, Huvos A, Lane J, Marcove R, Applewhite A, Vlamis V and Rosen G: Chemotherapy for nonmetastatic osteogenic sarcoma: The Memorial Sloan-Kettering experience. J Clin Oncol 10: 5-15, 1992. 
28. Eilber FR and Rosen G: Adjuvant chemotherapy for osteosarcoma. Semin Oncol 16: 312-322, 1989.

29. Rosen G: Neoadjuvant chemotherapy for osteogenic sarcoma: A model for the treatment of other highly malignant neoplasms. Recent Results Cancer Res 103: 148-157, 1986.

30. Su W, Lai Z, Wu F, Lin Y, Mo Y, Yang Z and Wu J: Clinical efficacy of preoperative chemotherapy with or without ifosfamide in patients with osteosarcoma of the extremity: Meta-analysis of randomized controlled trials. Med Oncol 32: 481, 2015.

31. Li S, Sun W, Wang H, Zuo D, Hua Y and Cai Z: Research progress on the multidrug resistance mechanisms of osteosarcoma chemotherapy and reversal. Tumor Biol 36: 1329-1338, 2015.

32. van Dalen EC, van der Pal HJ, Caron HN and Kremer LC: Different dosage schedules for reducing cardiotoxicity in cancer patients receiving anthracycline chemotherapy. Cochrane Database Syst Rev: CD005008, 2006.

33. Liu Y, Xu Y, Lin N, Jiang S, Wang Y and Ye Z: High-dose methotrexate (HD-MTX) used as an adjunct with other chemotherapeutics for the treatment of osteosarcoma. Cell Biochem Biophys 71: 1097-1104, 2015

34. Holmboe L, Andersen AM, Mørkrid L, Slørdal L and Hall KS: High dose methotrexate chemotherapy: Pharmacokinetics, folate and toxicity in osteosarcoma patients. Br J Clin Pharmacol 73: 106-114, 2012.

35. Zhang W, Zhang Q, Zheng TT, Zhen JC and Niu XH: Delayed high-dose methotrexate excretion and influencing factors in osteosarcoma patients. Chin Med J (Engl) 129: 2530-2534 2016.

36. Kaneko T, Fujioka T, Suzuki Y, Sato Y and Itoh H: Performance characteristics between TDx ${ }^{\circledR} \mathrm{FLx}$ and $\mathrm{TBA}^{\mathrm{TM}}-25 \mathrm{FR}$ for the therapeutic drug monitoring of methotrexate. J Pharm Health Care Sci 2: 7, 2016.

37. Yu W, Tang L, Lin F, Yao Y and Shen Z: Pirarubicin versus doxorubicin in neoadjuvant/adjuvant chemotherapy for stage IIB limb high-grade osteosarcoma: Does the analog matter? Med Onco 32: 307, 2015.

38. Kobys VL, Konovalenko VF, Repina NV, Golovko TS, Gulak LO, Tarasova TO, Zaharycheva EV and Matyushok OF: Treatment of large osteosarcoma in children: New approach. Exp Oncol 35: $105-108,2013$

39. He F, Zhang W, Shen Y, Yu P, Bao Q, Wen J, Hu C and Qiu S: Effects of resection margins on local recurrence of osteosarcoma in extremity and pelvis: Systematic review and meta-analysis. Int J Surg 36: 283-292, 2016.

40. Liu ZL, Wang G, Peng AF, Luo QF, Zhou Y and Huang SH: Fatty acid synthase expression in osteosarcoma and its correlation with pulmonary metastasis. Oncol Lett 4: 878-882, 2012.

41. Sampson VB, Gorlick R, Kamara D and Anders Kolb E: A review of targeted therapies evaluated by the pediatric preclinical testing program for osteosarcoma. Front Oncol 31: 132, 2013.

42. Huang YJ, He AN, Sun YJ, Shen Z, Min DL and Yao Y: Continuous-infusion ifosfamide and doxorubicin combination as second-line chemotherapy for recurrent or refractory osteosarcoma patients in China: A retrospective study. Asian Pac J Cancer Prev 16: 2391-2395, 2015.

43. Ottaviani $\mathrm{G}$ and Jaffe N: The epidemiology of osteosarcoma Cancer Treat Res 152: 3-13, 2009.

44. Hattinger CM, Vella S, Tavanti E, Fanelli M, Picci P and Serra M: Pharmacogenomics of second-line drugs used for treatment of unresponsive or relapsed osteosarcoma patients. Pharmacogenomics 17: 2097-2114, 2016.

45. Duffaud F, Egerer G, Ferrari S, Rassam H, Boecker U and Bui-Nguyen B: A phase II trial of second-line pemetrexed in adults with advanced/metastatic osteosarcoma. Eur J Cancer 48: 564-570, 2012

46. Heymann MF, Brown HK and Heymann D: Drugs in early clinical development for the treatment of osteosarcoma. Expert Opin Investig Drugs 25: 1265-1280, 2016.

47. Lee JA, Paik EK, Seo J, Kim DH, Lim JS, Yoo JY and Kim MS Radiotherapy and gemcitabine-docetaxel chemotherapy in children and adolescents with unresectable recurrent or refractory osteosarcoma. Jpn J Clin Oncol 46: 138-143, 2016.

48. Qi WX, He AN, Tang LN, Shen Z, Lin F and Yao Y: Efficacy and safety of gemcitabine-docetaxel combination therapy for recurrent or refractory high-grade osteosarcoma in China: A retrospective study of 18 patients. Jpn J Clin Oncol 42: 427-431, 2012.

49. Wang DZ, Gao JF, Jing SF, Wei H, Huang XY and Li CD: Antitumor effect of docetaxel in osteosarcoma by the inhibition of Wnt signal channel. Drug Res (Stuttg) 65: 597-601, 2015.
50. Choi J, Ko E, Chung HK, Lee JH, Ju EJ, Lim HK, Park I, Kim KS, Lee JH, Son WC, et al: Nanoparticulated docetaxel exerts enhanced anticancer efficacy and overcomes existing limitations of traditional drugs. Int J Nanomedicine 10: 6121-6132, 2015.

51. He A, Qi W, Huang Y, Sun Y, Shen Z, Zhao H, Yang Y and Yao Y: Comparison of pirarubicin-based versus gemcitabine-docetaxel chemotherapy for relapsed and refractory osteosarcoma: A single institution experience. Int J Clin Oncol 18: 498-505, 2013

52. Xiao X, Wang W, Zhang H, Gao P, Fan B, Huang C, Fu J, Chen G, Shi L, Zhu H, et al: Individualized chemotherapy for osteosarcoma and identification of gene mutations in osteosarcoma. Tumour Biol 36: 2427-2435, 2015.

53. Palmerini E, Jones RL, Marchesi E, Paioli A, Cesari M, Longhi A, Meazza C, Coccoli L, Fagioli F, Asaftei S, et al: Gemcitabine and docetaxel in relapsed and unresectable high-grade osteosarcoma and spindle cell sarcoma of bone. BMC Cancer 16: 280, 2016

54. Zwerdling T, Krailo M, Monteleone P, Byrd R, Sato J, Dunaway R, Seibel N, Chen Z, Strain J and Reaman G; Children's Oncology Group: Phase II investigation of docetaxel in pediatric patients with recurrent solid tumors: A report from the Children's Oncology Group. Cancer 106: 1821-1828, 2006.

55. Song BS, Seo J, Kim DH, Lim JS, Yoo JY and Lee JA: Gemcitabine and docetaxel for the treatment of children and adolescents with recurrent or refractory osteosarcoma: Korea cancer center hospital experience. Pediatr Blood Cancer 61: 1376-1381, 2014.

56. Lee JA, Jeon DG, Cho WH, Song WS, Yoon HS, Park HJ, Park BK, Choi HS, Ahn HS, Lee JW, et al: Higher gemcitabine dose was associated with better outcome of osteosarcoma patients receiving gemcitabine-docetaxel chemotherapy. Pediatr Blood Cancer 63: 1552-1556, 2016.

57. Strippoli S, Traversa M, Cramarossa A, Popescu O, Lorusso V and Guida M: Long-term response of gemcitabine plus docetaxel chemotherapy regimen for extraskeletal osteosarcoma: A case report. Oncol Lett 9: 2567-2571, 2015.

58. Yu WX, Tang LN, Lin F, Yao Y and Shen Z: Comparison of pemetrexed plus cisplatin with gemcitabine plus docetaxel in refractory/metastatic osteosarcoma: Clinical outcomes from a retrospective database monitored in a single institute. Oncol Lett 8: 2243-2248, 2014

59. Mora J, Cruz CO, Parareda A and de Torres C: Treatment of relapsed/refractory pediatric sarcomas with gemcitabine and docetaxel. J Pediatr Hematol Oncol 31: 723-729, 2009.

60. O'Day K and Gorlick R: Novel therapeutic agents for osteosarcoma. Expert Rev Anticancer Ther 9: 511-523, 2009.

61. Grignani G, Palmerini E, Dileo P, Asaftei SD, D'Ambrosio L, Pignochino Y, Mercuri M, Picci P, Fagioli F, Casali PG, et al: A phase II trial of sorafenib in relapsed and unresectable high-grade osteosarcoma after failure of standard multimodal therapy: An Italian Sarcoma Group study. Ann Oncol 23: 508-516, 2012.

62. Grignani G, Palmerini E, Ferraresi V, D'Ambrosio L, Bertulli R, Asaftei SD, Tamburini A, Pignochino Y, Sangiolo D, Marchesi E, et al: Sorafenib and everolimus for patients with unresectable high-grade osteosarcoma progressing after standard treatment: A non-randomised phase 2 clinical trial. Lancet Oncol 16: 98-107, 2014.

63. Magnan H, Goodbody CM, Riedel E, Pratilas CA, Wexler LH and Chou AJ: Ifosfamide dose-intensification for patients with metastatic Ewing sarcoma. Pediatr Blood Cancer 62: 594-597, 2015.

64. Liu L and Bhatoolaul N: Endostar as a perioperative regimen with chemotherapy in osteosarcoma: A Review. Biomed Lett 2: 60-65, 2016.

65. Hattinger CM, Tavanti E, Fanelli M, Vella S, Picci P and Serra M. Pharmacogenomics of genes involved in antifolate drug response and toxicity in osteosarcoma. Expert Opin Drug Metab Toxicol 13: 245-257, 2016

66. Zhu X, Du X, Deng X, Yi H, Cui S, Liu W, Shen A and Cui Z: C6 ceramide sensitizes pemetrexed-induced apoptosis and cytotoxicity in osteosarcoma cells. Biochem Biophys Res Commun 452: 72-78, 2014.

67. Xu M, Xu CX, Bi WZ, Song ZG, Jia JP, Chai W, Zhang LH and Wang Y. Effects of endostar combined multidrug chemotherapy in osteosarcoma. Bone 57: 111-115, 2013

68. Venkatakrishnan K, Kramer WG, Synold TW, Goodman DB, Sides E III and Oliva C: A pharmacokinetic, pharmacodynamic, and electrocardiographic study of liposomal mifamurtide (L-MTP-PE) in healthy adult volunteers. Eur J Clin Pharmacol 68: 1347-1355, 2012. 
69. Mori K, Ando K and Heymann D: Liposomal muramyl tripeptide phosphatidyl ethanolamine: A safe and effective agent against osteosarcoma pulmonary metastases. Expert Rev Anticancer Ther 8: 151-159, 2008

70. Anderson PM, Wiseman GA, Dispenzieri A, Arndt CA, Hartmann LC, Smithson WA, Mullan BP and Bruland OS: High-dose samarium-153 ethylene diamine tetramethylene phosphonate: Low toxicity of skeletal irradiation in patients with osteosarcoma and bone metastases. J Clin Oncol 20: 189-196, 2002.

71. Lin F, Zheng SE, Shen Z, Tang LN, Chen P, Sun YJ, Zhao H and Yao Y: Relationships between levels of CXCR4 and VEGF and blood-borne metastasis and survival in patients with osteosarcoma. Med Oncol 28: 649-653, 2011.

72. Qu L and Liu B: Cyclooxygeanse-2 promotes metastasis in osteosarcoma. Cancer Cell Int 15: 69, 2015.

73. Kleinerman ES (ed): Current advances in osteosarcoma. Springer International Publishing Switzerland 35: 594, 2014.

74. Endo-Munoz L, Evdokiou A and Saunders NA: The role of osteoclasts and tumour-associated macrophages in osteosarcoma metastasis. Biochim Biophys Acta 1826: 434-442, 2012.

75. Luetke A, Meyers PA, Lewis I and Juergens H: Osteosarcoma treatment-where do we stand? A state of the art review. Cancer Treat Rev 40: 523-532, 2014.

76. Geller DS and Gorlick R: Osteosarcoma: A review of diagnosis, management, and treatment strategies. Clin Adv Hematol Oncol 8: 705-718, 2010.

77. Chou AJ, Geller DS and Gorlick R: Therapy for osteosarcoma: Where do we go from here? Paediatr Drugs 10: 315-327, 2008.

78. van Oosterwijk JG,AnningaJK, Gelderblom H,Cleton-Jansen AM and Bovée JV: Update on targets and novel treatment options for high-grade osteosarcoma and chondrosarcoma. Hematol Oncol Clin North Am 27: 1021-1048, 2013.
79. Savage SA and Mirabello L: Using epidemiology and genomics to understand osteosarcoma etiology. Sarcoma 2011: 548151, 2011.

80. ESMO/European Sarcoma Network Working Group: Bone sarcomas: ESMO clinical practice guidelines for diagnosis, treatment and follow-up. Ann Oncol 25 (Suppl 3): iii113-iii123

81. Wang J and Li G: Mechanisms of methotrexate resistance in osteosarcoma cell lines and strategies for overcoming this resistance. Oncol Lett 9: 940-944, 2015.

82. Isakoff MS, Bielack SS, Meltzer P and Gorlick R: Osteosarcoma: Current treatment and a collaborative pathway to success. J Clin Oncol 33: 3029-3035, 2015.

83. Miller BJ, Cram P, Lynch CF and Buckwalter JA: Risk factors for metastatic disease at presentation with osteosarcoma: An analysis of the SEER database. J Bone Joint Surg Am 95: e89, 2013.

84. Botter SM, Neri D and Fuchs B: Recent advances in osteosarcoma. Curr Opin Pharmacol 16: 15-23, 2014.

85. Rapkin L, Qayed M, Brill P, Martin M, Clark D, George BA, Olson TA, Wasilewski-Masker K, Alazraki A and Katzenstein HM: Gemcitabine and docetaxel (GEMDOX) for the treatment of relapsed and refractory pediatric sarcomas. Pediatr Blood Cancer 59: 854-858, 2012.

86. Gosiengfiao Y, Reichek J, Woodman J, Ben-Ami T and Walterhouse D: Gemcitabine with or without docetaxel and resection for recurrent osteosarcoma: The experience at children's memorial hospital. J Pediatr Hematol Oncol 34: e63-e65, 2012. 